\title{
RESEARCH
}

Open Access

\section{Survival of pediatric patients after cardiopulmonary resuscitation for in- hospital cardiac arrest: a systematic review and meta-analysis}

Melaku Bimerew ${ }^{1 *}$ (D), Adam Wondmieneh ${ }^{1}$, Getnet Gedefaw ${ }^{2}$, Teshome Gebremeskel ${ }^{1}$, Asmamaw Demis ${ }^{1}$ and Addisu Getie ${ }^{1}$

\begin{abstract}
Background: In-hospital cardiac arrest is a major public health issue. It is a serious condition; most probably end up with death within a few minutes even with corrective measures. However, cardiopulmonary resuscitation is expected to increase the probability of survival and prevent neurological disabilities in patients with cardiac arrest. Having a pooled prevalence of survival to hospital discharge after cardiopulmonary resuscitation is vital to develop strategies targeted to increase probability of survival among patients with cardiac arrest. Therefore, this systematic review and meta-analysis was aimed to assess the pooled prevalence of survival to hospital discharge among pediatric patients who underwent cardiopulmonary resuscitation for in-hospital cardiac arrest.

Methods: PubMed, Google Scholar, and Cochrane review databases were searched. To have current (five-year) evidence, only studies published in 2016 to 2020 were included. The weighted inverse variance random-effects model at $95 \% \mathrm{Cl}$ was used to estimate the pooled prevalence of survival. Heterogeneity assessment, test of publication bias, and subgroup analyses were also employed accordingly.

Results: Twenty-five articles with a total sample size of 28,479 children were included in the final analysis. The pooled prevalence of survival to hospital discharge was found to be $46 \%\left(95 \% \mathrm{Cl}=43.0-50.0 \% ; 1^{2}=96.7 \% ; p<0.001\right)$. Based on subgroup analysis by "continent" and "income level", lowest prevalence of pooled survival was observed in Asia (six studies; pooled survival $=36.0 \%$ with $95 \% \mathrm{Cl}=19.01-52.15 \% ; I^{2}=97.4 \% ; p<0.001$ ) and in low and middle income countries (six studies, pooled survival $=34.0 \%$ with $95 \% \mathrm{Cl}=17.0-51.0 \%, 12=97.67 \%, p<0.001$ ) respectively.

Conclusion: Although there was an extremely high heterogeneity among reported results $\left(1^{2}=96.7 \%\right)$, in this metaanalysis more than half of pediatric patients (54\%) who underwent cardiopulmonary resuscitation for in-hospital cardiac arrest did not survived to hospital discharge. Therefore, developing further strategies and encouraging researches might be crucial.
\end{abstract}

Keywords: Cardiopulmonary resuscitation, Pediatric, Survival to hospital discharge

\footnotetext{
*Correspondence: mebiget@gmail.com

'Department of Nursing, College of Health Sciences, Woldia University, Woldia, Ethiopia

Full list of author information is available at the end of the article
}

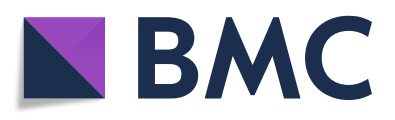

(- The Author(s). 2021 Open Access This article is licensed under a Creative Commons Attribution 4.0 International License, which permits use, sharing, adaptation, distribution and reproduction in any medium or format, as long as you give appropriate credit to the original author(s) and the source, provide a link to the Creative Commons licence, and indicate if changes were made. The images or other third party material in this article are included in the article's Creative Commons licence, unless indicated otherwise in a credit line to the material. If material is not included in the article's Creative Commons licence and your intended use is not permitted by statutory regulation or exceeds the permitted use, you will need to obtain permission directly from the copyright holder. To view a copy of this licence, visit http://creativecommons.org/licenses/by/4.0/. The Creative Commons Public Domain Dedication waiver (http://creativecommons.org/publicdomain/zero/1.0/) applies to the data made available in this article, unless otherwise stated in a credit line to the data. 


\section{Background}

Cardiac arrest is a medical emergency characterized by cessation of cardiac activity. It leads to unresponsiveness; with no normal breathing, and no signs of circulation $[1,2]$. It might be originated from the heart, lung, brain. Sometimes, toxic overdoses and severe infections might also be a cause $[3,4]$. Cardiac arrest is a life-threatening condition and most probably ends up with death within a few minutes. In adults, cardiac arrest is commonly due to primary cardiac abnormalities. But, in children, it is most often the result of apnea or respiratory failure leading to bradycardia and pulseless electrical activity [2, 5]. Based on the location of arrest, it can be classified as in-hospital cardiac arrest-cessation of cardiac activity in hospitalized patients; or out-of-hospital cardiac arrest-an arrest occurred in outpatient settings (in the community) [6].

In-hospital cardiac arrest is a major public health issue which almost ends up with death both in adults and children [7]. The global prevalence of in-hospital cardiac arrest is not well documented. But, each year, nearly 1 million cases of cardiac arrest are recorded in Europe and United States [2, 8, 9]. Similarly, about 2-6\% of children admitted to pediatric intensive care units are estimated to be victims of cardiac arrest [1]. About $60 \%$ of cardiac arrest cases among the pediatric population occurs in younger children or infants $[4,5]$. Probability of survival after in-hospital cardiac arrest is low. More than $75 \%$ of the victims are estimated to die. One-third of the survivors will have neurological malfunctions $[1,5]$. Hence, it is a threatening condition for families of the patient and healthcare providers. Furthermore, it is associated with devoting huge amounts of healthcare resources $[7,10]$.

Worldwide, different treatment strategies are implemented to reverse the ceased cardiac activity and to increase the probability of survival in children with cardiac arrest $[4,11,12]$. Cardiopulmonary resuscitation (CPR) is one of those strategies; comprising basic airway management, artificial ventilation, and chest compressions targeted to provide oxygen and nutrients for core organs: the heart, brain, and lungs. By doing so, CPR is expected to increase the probability of survival in patients with cardiac arrest [13]. It was implemented since 1966 with a well-defined, written procedural guidelines [14]. Additionally, prevention and prompt treatment of respiratory failure can prevent or reduce cardiac arrest in children [2].

Several studies were conducted to assess the success rate of $C P R$ in terms of survival to hospital discharge among pediatric patients. However, reported results from those studies were inconsistent; with survival to hospital discharge ranging from 0 to $80 \%[15,16]$. Having a pooled prevalence of survival to hospital discharge after CPR is vital to develop further strategies targeted to increase probability of survival among patients with cardiac arrest. Despite of this, there is no current and updated pooled prevalence showing the overall survival to hospital discharge after CPR in pediatric patients [17]. Therefore, the purpose of this systematic review and meta-analysis was to assess the pooled prevalence of survival to hospital discharge among pediatric patients (age $<21$ years) who underwent CPR for in-hospital cardiac arrest.

\section{Methods \\ Reporting}

This systematic review and meta-analysis has been presented according to the Preferred Reporting Items for Systematic Review and Meta-Analysis (PRISMA) guideline [18] (Additional file 1).

\section{Searching strategies}

PubMed, Google Scholar, and Cochrane review databases were searched to identify relevant studies. The searching was also extended to repositories. Snowball searching was also employed to accommodate potentially related articles. The comprehensive searching strategy was developed by using different Boolean operators via Population Intervention Comparison and Outcome (PICO) standard questions. The core searching terms and phrases were "Cardiopulmonary Resuscitation", "CPR", "ECPR", "In-hospital cardiac arrest", "Success rate", "Survival to hospital discharge" "Pediatric", "Children", "Infants" and "Neonates". We had used these core terms in combination using the Boolean operators i.e. "AND" or "OR". Filters were used to limit year of publication by applying the term "since 2016 " or by bounding publication year range as "2016-2020."

\section{Eligibility criteria}

All published or unpublished observational studies (cross-sectional, case-control, and cohort designs) conducted to assess the prevalence of survival to hospital discharge after cardiopulmonary resuscitation in pediatric patients (age $<21$ years) [19] were included. To have current evidence on survival to hospital discharge after CPR, only research articles published since 2016 were included. But, citations, research articles which did not report the outcome variable, if full text was not accessible, case presentations, or articles conducted on animals were excluded.

\section{Patient and public involvement}

Patients or the public were not involved in the design, or conduct, or reporting, or dissemination plans of this meta-analysis. 


\section{Outcome variable}

The outcome variable was survival to hospital discharge in pediatric patients after CPR for in-hospital cardiac arrest.

\section{Quality assessment}

After removing duplicate studies and screening potentially relevant articles, two independent authors $(\mathrm{MB}$ and AG) appraised the quality of eligible articles by using the nine score Newcastle-Ottawa Scale (NOS) for cohort studies [20] as a quality appraisal tool. Disagreements between appraisers were solved by taking their mean scores. Studies having "good" or "fair" quality based on the thresholds for converting the NOS score to the Agency for Healthcare Research and Quality (AHRQ) standards were considered as low risk and included in the final analysis; but studies with poor quality were excluded from the final analysis (Additional file 2).

\section{Data extraction and statistical analysis}

The data was extracted and cleaned by using Microsoft Excel worksheet. After extraction, it was exported to
STATA statistical software version 11.0. for further analysis; standard errors for the prevalence of the outcome variable (survival to hospital discharge) was calculated by using the binomial distribution formula [21]. The overall prevalence for the outcome variable was pooled based on the weighted inverse variance random-effects model at 95\%CI. Results were presented using narrative synthesis, tables, and forest plots. Heterogeneity between included studies was assessed by the Inverse Variance $\left(\mathrm{I}^{2}\right)$ with $p$-values. The values of $\mathrm{I}^{2}, 25,50$, and $75 \%$ represent low, moderate, and high heterogeneity respectively [22]. Publication bias was assessed by funnel plots and Egger's regression test [23]. Subgroup analysis by study area/ continent, income level and year of publication was also conducted.

\section{Results}

Study selection and characteristics of the included studies A total of 1646 research articles were retrieved from the comprehensive electronic searching. Of them, 25 articles $[16,24-47]$ were included in the final analysis (Fig. 1). All the included articles were cohort in their study design (Table 1).

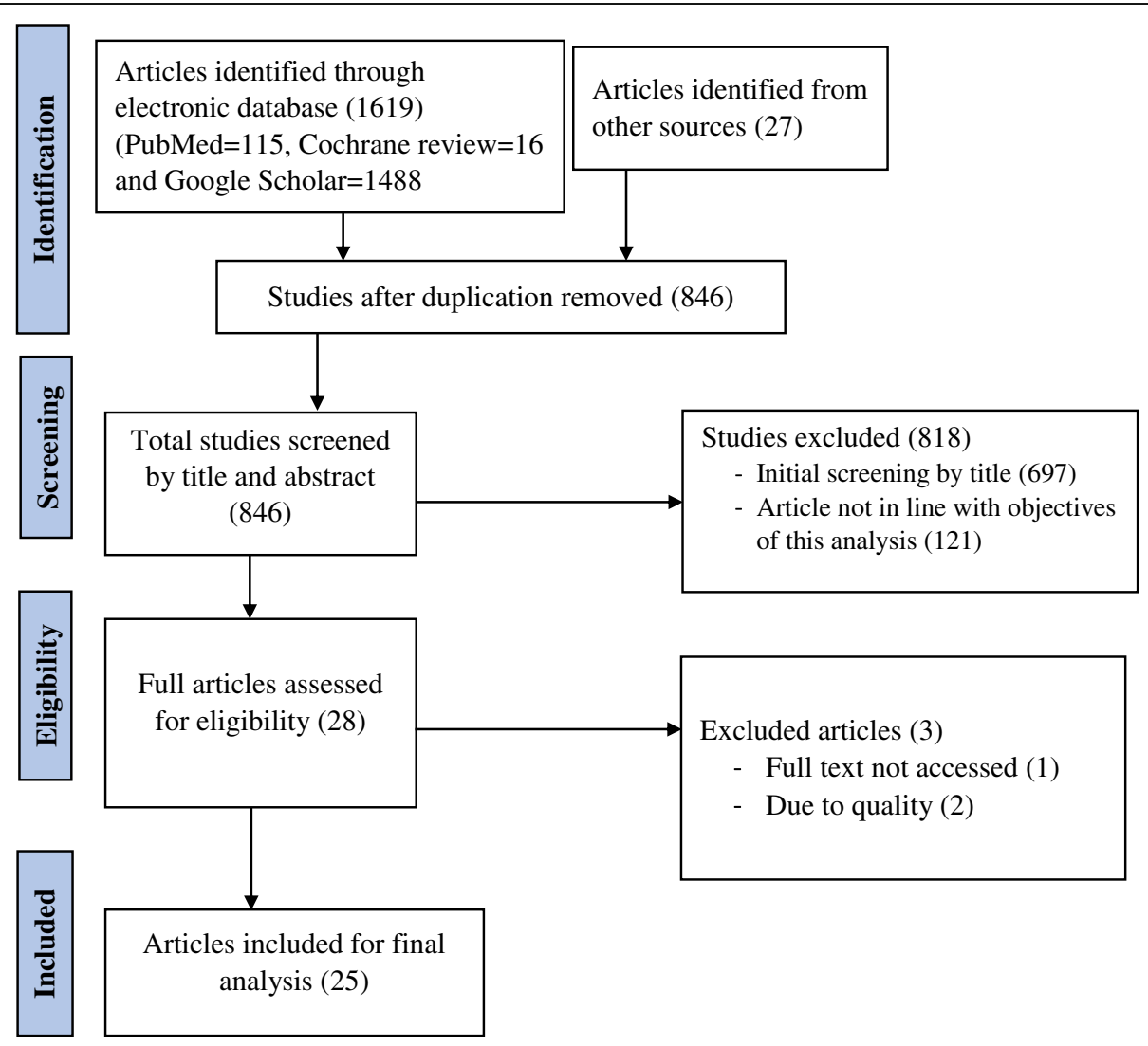

Fig. 1 PRISMA flow diagram showing searching strategies, reasons for exclusion, and number of included research articles in this systematic review and meta-analysis, 2020 
Table 1 Characteristics of research articles included in this systematic review and meta-analysis, 2020

\begin{tabular}{|c|c|c|c|c|c|c|c|}
\hline S. No & Author & Publi cation year & Country & Continent & Income level & Sample size & $\begin{array}{l}\text { SHD } \\
\text { (\%) }\end{array}$ \\
\hline 1 & Appiah J et al. [24] & 2018 & South Africa & Africa & Upper-middle income & 83 & 62.65 \\
\hline 2 & Shikuku DN et al. [25] & 2018 & Kenya & Africa & Lower-middle income & 24 & 45.83 \\
\hline 3 & Alten et al. [26] & 2017 & North America & America & High income & 470 & 54.04 \\
\hline 4 & Anton-Martin P et al. [27] & 2020 & United states & America & High income & 73 & 43.84 \\
\hline 5 & Barbaro RP et al. [28] & 2017 & United states & America & High income & 8575 & 41.94 \\
\hline 6 & Berg et al. [29] & 2016 & United states & America & High income & 139 & 45.32 \\
\hline 7 & Berg et al. [30] & 2018 & United states & America & High income & 164 & 46.95 \\
\hline 8 & Beshish AG et al. [31] & 2018 & Michigan & America & High income & 80 & 47.50 \\
\hline 9 & Brown S et al. [32] & 2018 & Washington & America & High income & 52 & 48.08 \\
\hline 10 & Burke CR et al. [33] & 2017 & United states & America & High income & 53 & 49.06 \\
\hline 11 & Foglia et al. [34] & 2017 & Pennsylvania & America & High income & 113 & 61.06 \\
\hline 12 & Geisser D et al. [35] & 2019 & Massachusetts & America & High income & 295 & 41.69 \\
\hline 13 & Holmberg et al. [36] & 2019 & United states & America & High income & 13,184 & 45.50 \\
\hline 14 & Hornik et al. [37] & 2016 & North America & America & High income & 2231 & 50.52 \\
\hline 15 & Shakoor A et al. [38] & 2019 & New York & America & High income & 70 & 54.29 \\
\hline 16 & Torres-Andres et al. [39] & 2018 & United states & America & High income & 55 & 67.27 \\
\hline 17 & Assar S et al. [40] & 2016 & Iran & Asia & Upper-middle income & 279 & 11.83 \\
\hline 18 & Chen GL et al. [41] & 2018 & Asia pacific & Asia & Low income & 321 & 50.78 \\
\hline 19 & Erek et al. [42] & 2017 & Turkey & Asia & Upper-middle income & 25 & 20.00 \\
\hline 20 & Kabbani et al. [16] & 2019 & Saudi Arabia & Asia & High income & 15 & 80.00 \\
\hline 21 & Mok YH et al. [43] & 2016 & Singapore & Asia & High income & 51 & 45.10 \\
\hline 22 & Rathore V et al. [44] & 2016 & North India & Asia & Lower-middle income & 314 & 14.01 \\
\hline 23 & Adamski J et al. [45] & 2016 & Poland & Europe & High income & 285 & 53.33 \\
\hline 24 & Kramer P et al. [46] & 2020 & Germany & Europe & High income & 72 & 36.11 \\
\hline 25 & Skellett S et al. [47] & 2020 & United kingdom & Europe & High income & 1456 & 54.19 \\
\hline
\end{tabular}

SHD Survival to Hospital Discharge

\section{Survival to hospital discharge}

Twenty-five studies with a total sample size of $(n=28,479)$ had reported the prevalence of survival to hospital discharge in pediatric patients after CPR for in-hospital cardiac arrest with a lowest and highest prevalence of 11.8 and $80 \%$ respectively. The pooled prevalence of survival to hospital discharge in those patients was found to be $46.0 \%$ $\left(95 \% \mathrm{CI}=43.0-50.0 \% ; \mathrm{I}^{2}=96.7 \% ; p<0.001\right)$ (Fig. 2 ).

\section{Heterogeneity}

The inverse variance $\left(\mathrm{I}^{2}\right)$ was $96.7 \%$ with a $p$-value of $<0.001$ (Fig. 2); suggesting the presence of heterogeneity on the reported prevalence of survival to hospital discharge in pediatric patients who underwent CPR for in-hospital cardiac arrest among included studies.

\section{Sensitivity analysis}

By using the random-effects model, a leave-one-out sensitivity analysis was conducted to examine if the pooled magnitude of survival to hospital discharge was greatly impacted by the result of a single study. But, all the results of this sensitivity analysis were within the 95\% CI limits of the pooled magnitude (41.9-50.1\%); suggesting that there was no influential study potentially affected the observed pooled magnitude of survival to hospital discharge (Additional file 3).

\section{Publication bias}

Since the funnel plot showed symmetrical distribution (Additional file 4), and Egger's regression test was found insignificant (0.75), there was no evidence for publication bias in the included studies.

\section{Subgroup analysis}

Subgroup analysis was conducted by "year of publication" and the peak prevalence of survival was observed among studies published in 2018 with a pooled prevalence of $53.0 \%$. The pooled prevalence of survival to hospital discharge was 37.0, 48.0, 50.0, and 46.0\% among 


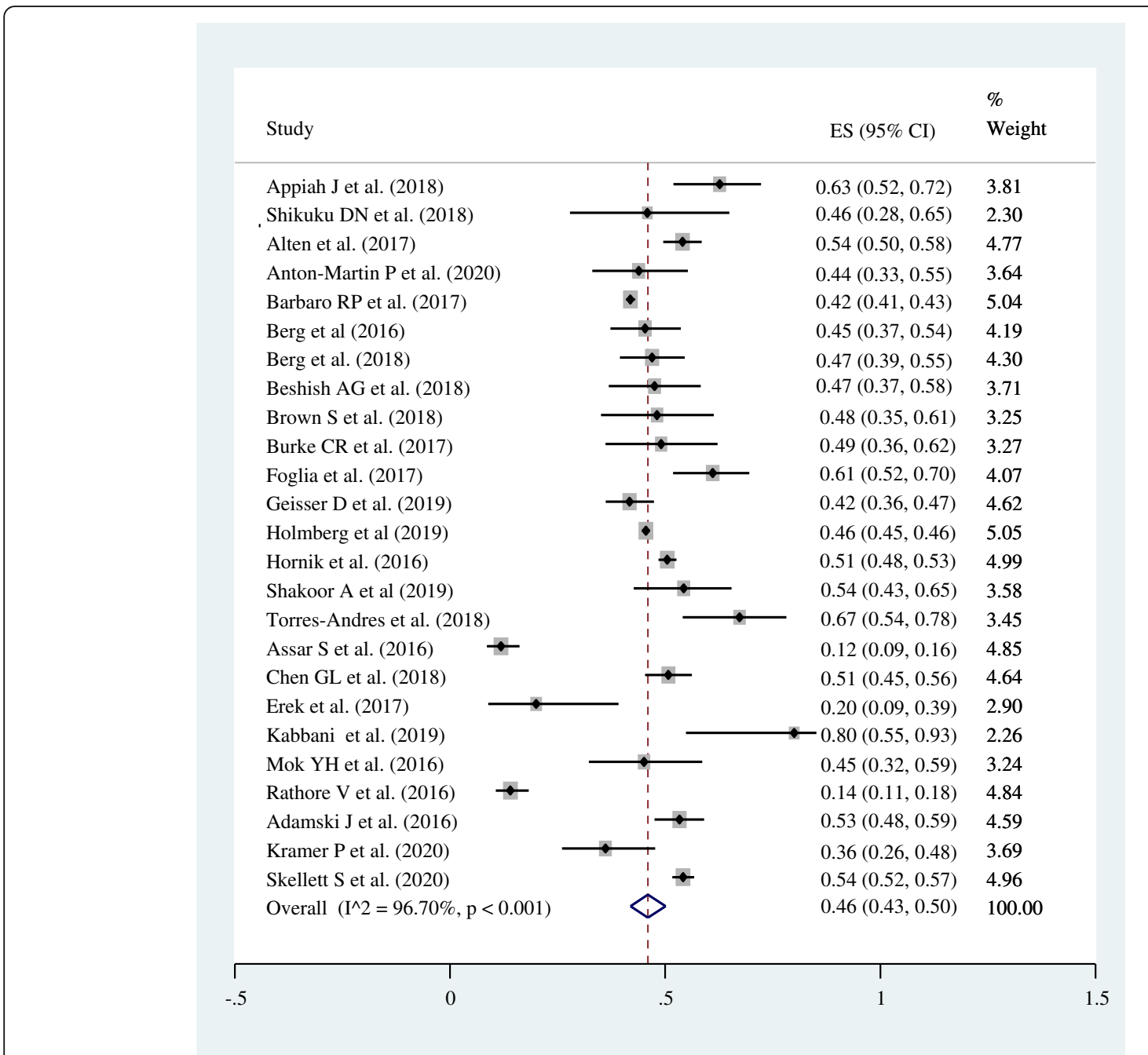

Fig. 2 Forest plot showing the pooled prevalence of survival to hospital discharge among pediatric patients who underwent cardiopulmonary resuscitation for in-hospital cardiac arrest, 2020

studies published in 2016, 2017, 2019, and 2020 respectively (Fig. 3).

Subgroup analysis was also conducted by "study area/ continents" to observe intercontinental disparities on survival to hospital discharge in pediatric patients who underwent CPR for in-hospital cardiac arrest. Lowest magnitude of pooled survival was observed in Asia (six studies; pooled survival $=36.0 \%$ with $\left.95 \% \quad \mathrm{CI}=19.0-52.0 \% ; \quad \mathrm{I}^{2}=97.4 \% ; \quad p<0.001\right)$ (Fig. 4).

Subgroup analysis was also conducted by "income level" to observe disparities on survival among low and middle income countries and high income countries. Lowest prevalence of pooled survival was observed in Low and middle income countries (six studies; pooled survival $=34.0 \%$ with $95 \% \mathrm{CI}=17.0-51.0 \% ; \mathrm{I}^{2}=97.7 \%$; $p<0.001$ ) (Fig. 5).

\section{Discussion}

A total of twenty-five research articles were included in this systematic review and meta-analysis. Nineteen studies were from high income countries and the remaining six studies were from low and middle income countries (Table 1). This indicates that studies addressing the issue of survival to hospital discharge in pediatric patients who underwent CPR for in-hospital cardiac arrest were limited in low and middle income countries. Therefore, the authors of this meta-analysis believe in a need for further research from those countries.

In this meta-analysis, the pooled prevalence of survival to hospital discharge in pediatric patients who underwent CPR for in-hospital cardiac arrest was found to be $46.0 \%$ (95\% CI $\left.=42.0-50.0 \% ; \mathrm{I}^{2}=96.8 \% ; p<0.001\right)$. This was in line with studies conducted in Spain [48] and United States [49]; as they had reported post-CPR 


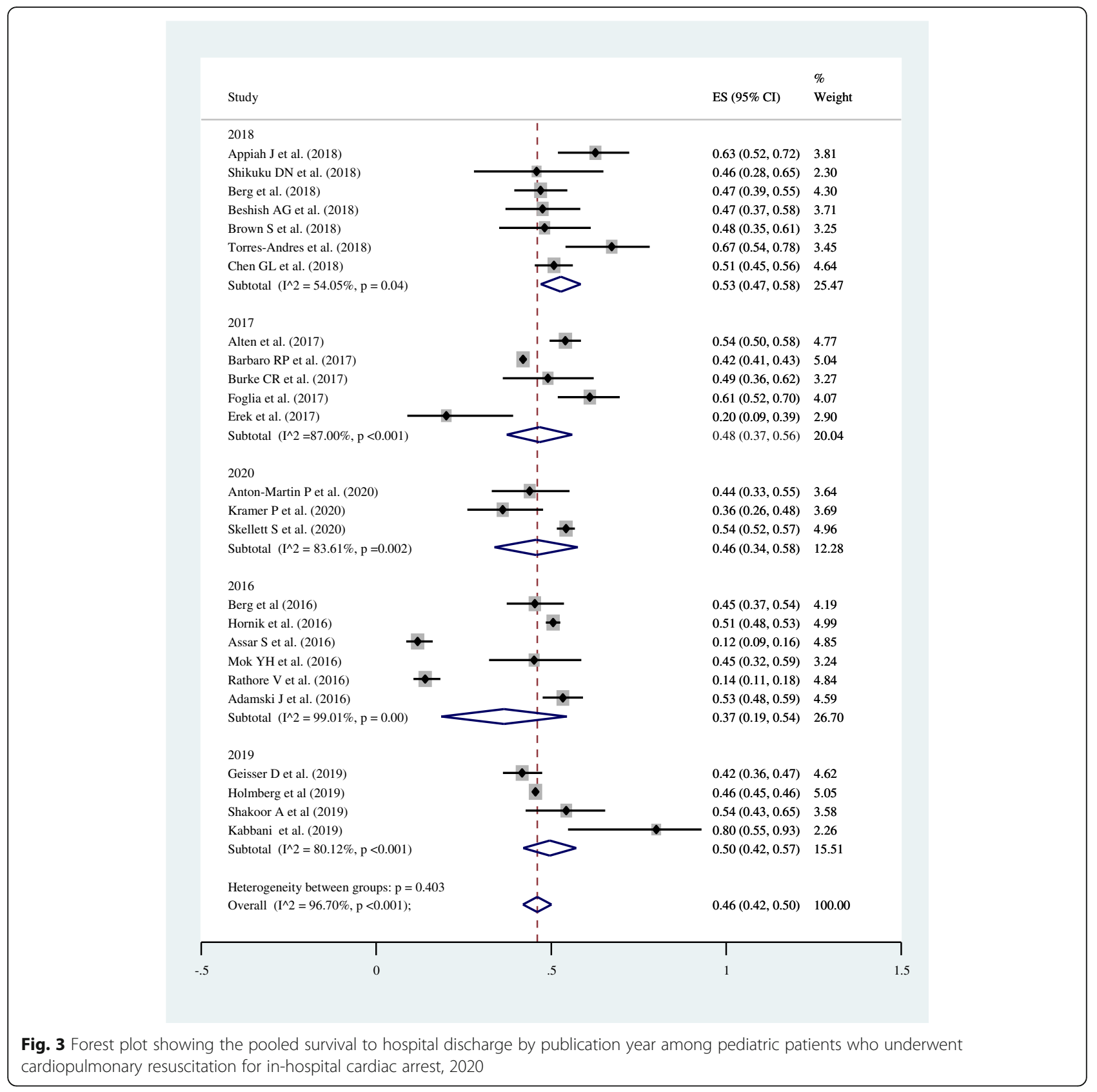

survival to hospital discharge in children to be 41 and $43.4 \%$ respectively. Lower prevalence of post-CPR survival to hospital discharge in children were reported from studies conducted in Taiwan (20.9\%) [50] and China (28.2\%) [51]. Findings of this meta-analysis was also higher than a global meta-analysis conducted by Phillips RS et al. [52]; as it had reported the pooled prevalence of survival to hospital discharge after CPR in children to be $37.2 \%$. Those inconsistencies might be due to differences in the study period.

Extremely high heterogeneity $\left(\mathrm{I}^{2}=96.7 \%\right)$ was observed among included studies in this meta-analysis.
Wider age ranges (birth - 21 years) among included studies might have been a possible source for this heterogeneity. Differences in CPR-type might have been also a possible source of heterogeneity; as eight studies used advanced technologies (Extracorporeal cardiopulmonary resuscitation (ECPR)) and others used conventional CPR or the combination of the two. Differences in etiology of the cardiac arrest might be also another possible source of this extreme heterogeneity. Whereas two studies included patients after surgery, some studies were conducted on patients with unspecified etiology of arrest, and other studies were conducted on neonates 


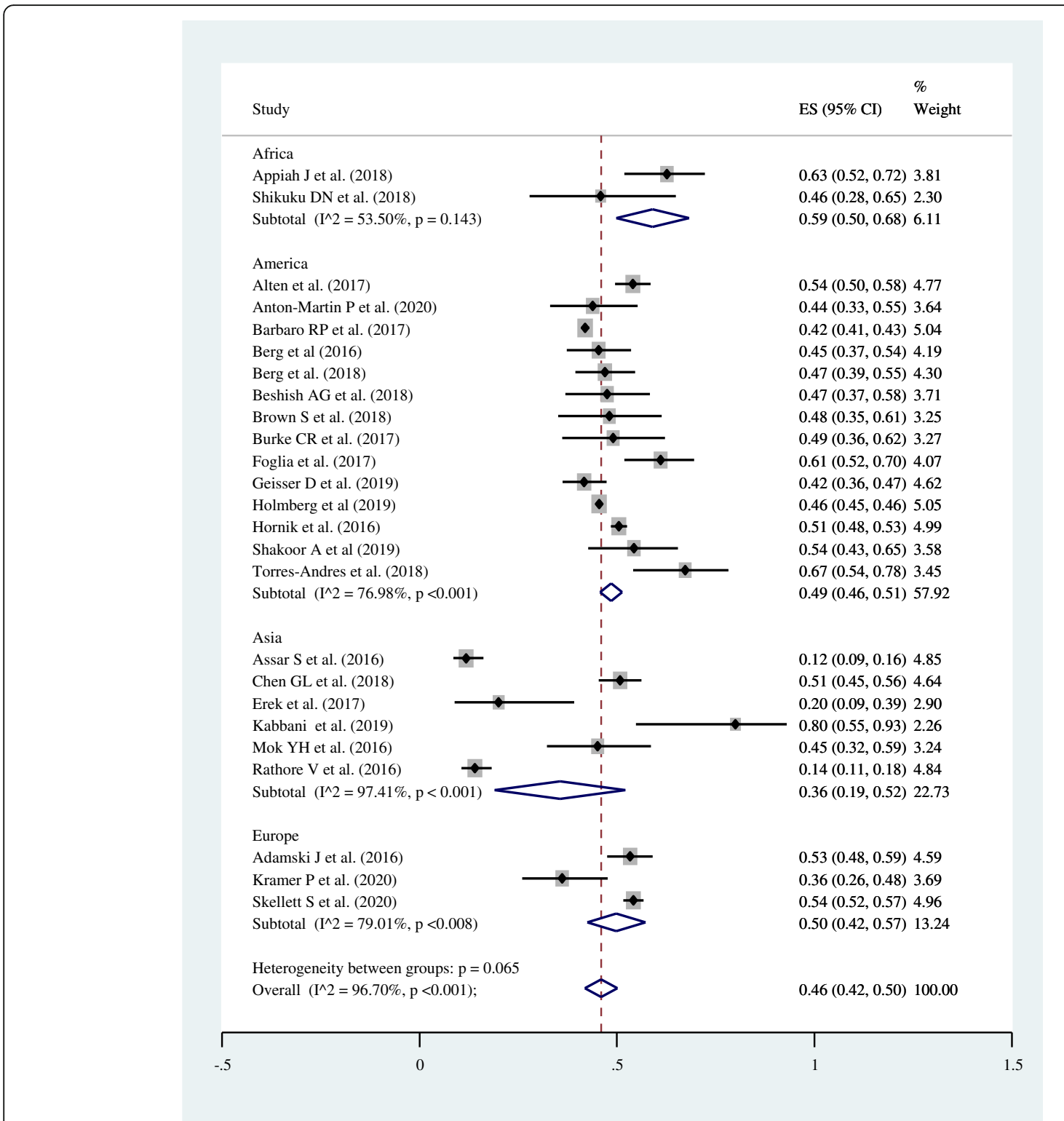

Fig. 4 Forest plot showing the intercontinental disparities in terms of survival to hospital discharge among pediatric patients who underwent cardiopulmonary resuscitation for in-hospital cardiac arrest, 2020

after birth. Differences in unit of the health institution where CPR was performed might have been also a possible source; as studies from pediatric intensive care units, neonatal intensive care units, cardiac intensive care units, general wards, and emergency departments were included.

Another possible source for the observed heterogeneity might be differences in time lag between conventional CPR and extracorporeal life support (ECLS), as one study reported a 30-min lag, one observed a 10-min lag, while others had not specified. Differences in inclusion criteria applied in individual included studies might be also a possible source for the observed heterogeneity; as some studies included patients who had CPR for at least $10 \mathrm{~min}$, while some included patients who had CPR for at least 1 min. Differences in socioeconomic status of the study area and time period might have been also a source for this heterogeneity. To reduce the higher heterogeneity observed in this meta-analysis, authors had employed subgroup analysis based on the possible sources of heterogeneity discussed above. But, unfortunately subgroup analysis was impossible due to overlaps in category of variables or missing information, except for publication year, continent/ study area, and income level.

Based on the subgroup analysis conducted by year of publication, the lowest prevalence of post-CPR 


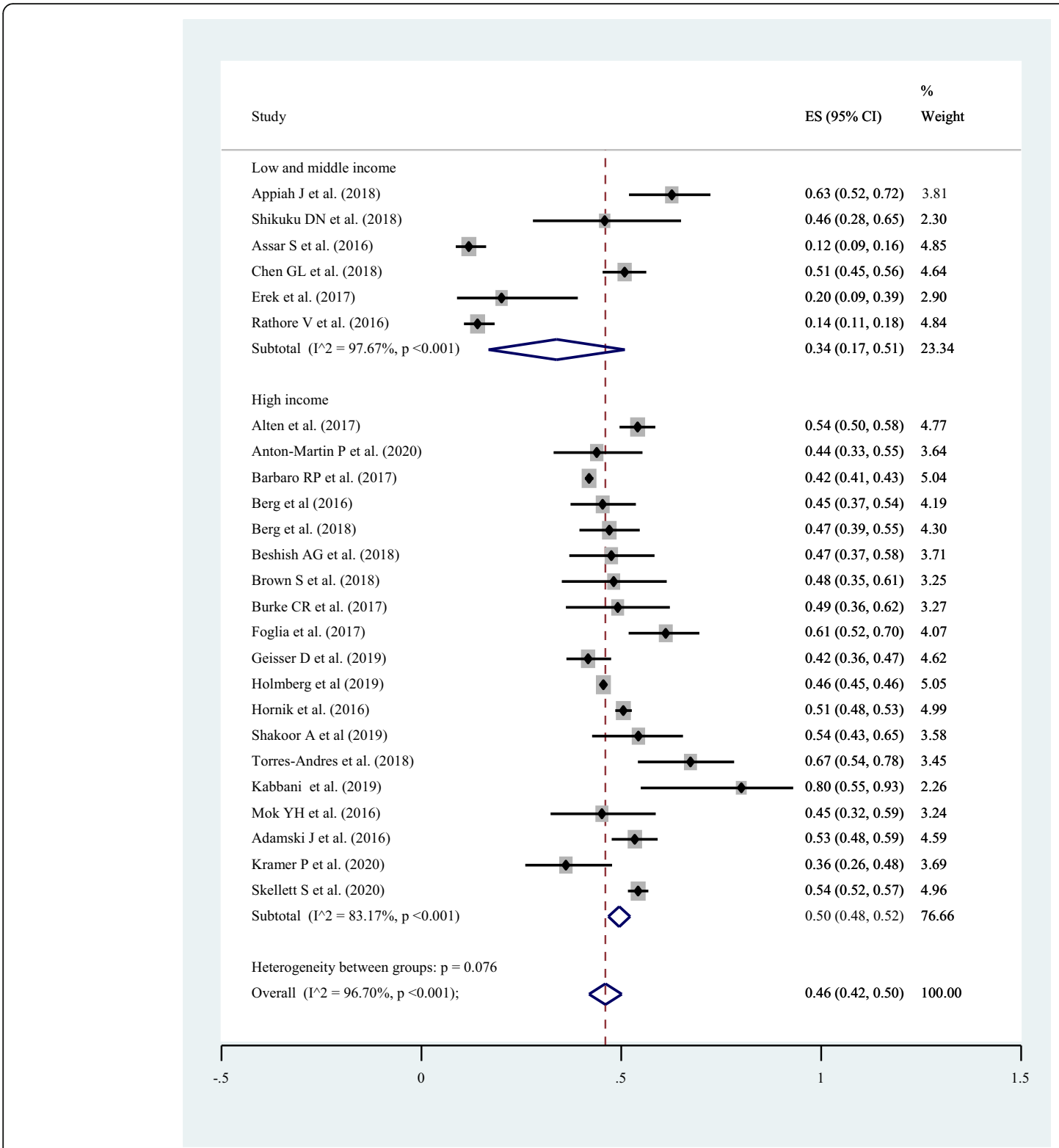

Fig. 5 Forest plot showing the disparities in terms of survival to hospital discharge among pediatric patients who underwent cardiopulmonary resuscitation in low and middle income and high income countries, 2020

survival (37.0\%) was recorded among articles published in 2016. On the other hand, the highest prevalence of survival was recorded among studies published in 2018. The general survival had increased from $36.5 \%$ in 2016 to $45.7 \%$ in 2020 ; due to the improvement in post CPR survival. This improvement might be due to technological advancements with time. In line with this meta-analysis, literature had also indicated that survival to hospital discharge after CPR had increased in the last few decades [49, 5356].

Intercontinental disparities in survival to hospital discharge were observed in this meta-analysis. The lowest
post-CPR survival (36.0\%) was recorded in Asia; which was consistent with a meta-analysis conducted by Yan et al. [57]. This might be due to lower socioeconomic status in Asia; as four of the six included studies from Asia were from low and middle income countries. On the other hand, the highest prevalence of survival was observed in Africa (59.0\%); but it was based on two studies with a total sample size of 107 which makes the observed pooled prevalence of survival to be a little evidence, and to be regarded with suspicion. Post-CPR survival to hospital discharge was nearly similar in America (49.0\%) and Europe (50.0\%). This might be due to similarities in socioeconomic status; as all included 
studies were from high income countries both in studies from America and Europe.

Based on the subgroup analysis by "income level", lower magnitude of post-CPR survival (34.0\%) was observed in low and middle income countries. In fact, low and middle income countries cannot afford prices for advanced CPR technologies like extracorporeal membrane oxygenation (ECMO) and cardioversion as can high income countries. Therefore, as revealed by this meta-analysis, low and middle income countries will have lower post-CPR survival than high income countries. Literature had also showed survival after CPR to be higher in developed countries than developing countries [57-59] which might be attributed to differences in technological and medical advancement. Additionally, a late referral to hospital for respiratory problems or failure could be the explanation of lowest survival in low and middle income countries.

\section{Strength and limitations}

In this meta-analysis, authors had used internationally qualified tools for evaluating the quality of included studies. Authors had also employed test for publication bias and subgroup analysis. However, this meta-analysis might not be free of limitations: specifically, publication bias might have occurred.

\section{Conclusion and future implications}

More than half (54\%) of CPR procedures in pediatric patients who underwent CPR for in-hospital cardiac arrest are unsuccessful in terms of survival to hospital discharge. Therefore, devoting efforts to develop further strategies based on new evidence might be crucial to improve clinical outcomes of CPR in children. Additionally, prevention and prompt treatment of respiratory problems should be emphasized to cardiac arrest in children. Researches from low and middle income countries addressing the issue of post-CPR survival were limited. Hence, low and middle income countries should develop CPR-registry systems like high income countries and encourage research on this issue. Furthermore, factors associated with survival to hospital discharge after CPR were not addressed in this meta-analysis. As a result, authors of this meta-analysis recommend to investigate further on this issue.

\section{Supplementary Information}

The online version contains supplementary material available at https://doi. org/10.1186/s13052-021-01058-9.

Additional file 1. PRISMA Checklist

Additional file 2: Table S1. The Newcastle-Ottawa Scale based quality assessment of included studies, 2020

Additional file 3: Table S2. A leave-one-out sensitivity analysis among included studies showing if the pooled magnitude of survival to hospital discharge was greatly impacted by the result of a single study, 2020
Additional file 4. Funnel plot showing the absence of publication bias (the symmetrical distribution of included research articles by the prevalence of survival to hospital discharge), 2020

\section{Acknowledgments}

We would like to acknowledge the authors of the included studies.

\section{Authors' contributions}

MB and AG conceived the research, reviewed relevant articles, assess the quality of the included articles, took part in extraction, statistical analysis and interpretation of data, in drafting the manuscript, and in revising it critically. AW, GG, TG, and AD took part in statistical analysis and interpretation of data, and in drafting the manuscript. All authors have read and approved the manuscript; agreed to submit to the current journal; and agreed to be accountable for all aspects of the work.

\section{Funding}

No funding was obtained for this systematic review and meta-analysis.

\section{Availability of data and materials}

The datasets used and/or analyzed during the current study are available within the manuscript.

\section{Declarations}

Ethics approval and consent to participate

Not applicable.

\section{Consent for publication}

Not applicable.

\section{Competing interests}

The authors declare that they have no competing interests.

\section{Author details}

${ }^{1}$ Department of Nursing, College of Health Sciences, Woldia University, Woldia, Ethiopia. ${ }^{2}$ Department of Midwifery, College of Health Sciences, Woldia University, Woldia, Ethiopia.

Received: 8 January 2021 Accepted: 26 April 2021

Published online: 29 May 2021

\section{References}

1. Tress EE, Kochanek PM, Saladino RA, Manole MD. Cardiac arrest in children. J Emergencies Trauma Shock. 2010;3(3):267.

2. Lenjani B, Baftiu N, Pallaska K, Hyseni K, Gashi N, Karemani N, et al. Cardiac arrest-cardiopulmonary resuscitation. J Acute Dis. 2014;3(1):31-5. https://doi. org/10.1016/S2221-6189(14)60007-X.

3. Richman PB, Nashed AH. The etiology of cardiac arrest in children and young adults: special considerations for ED management. Am J Emerg Med. 1999;17(3):264-70. https://doi.org/10.1016/S0735-6757(99)90122-5.

4. O'Connor R. Cardiopulmonary resuscitation (CPR) in infants and children. MSD Manual professional version 2020.

5. Molyneux E. Cardiopulmonary resuscitation in poorly resourced settings: better to pre-empt than to wait until it is too late: Taylor \& Francis; 2020

6. Herlitz J, Bång A, Ekström L, Aune S, Lundström G, Holmberg S, et al. A comparison between patients suffering in-hospital and out-of-hospital cardiac arrest in terms of treatment and outcome. J Intern Med. 2000;248(1): 53-60. https://doi.org/10.1046/j.1365-2796.2000.00702.x.

7. Arjunan P, Ramakrishnan TV, Gandhamaneni S. Characteristics and survival rates of patients experience in-hospital cardiac arrest: a retrospective study in a tertiary care Indian hospital. Bangladesh J Med Sci. 2020;19(3):537-42. https://doi.org/10.3329/bjms.v19i3.45872.

8. Yam N, McMullan DM. Extracorporeal cardiopulmonary resuscitation. Ann Transl Med. 2017;5(41):1-7.

9. Holmberg MJ, Ross CE, Fitzmaurice GM, Chan PS, Duval-Arnould J, Grossestreuer AV, et al. Annual incidence of adult and pediatric in-hospital cardiac arrest in the United States. Circ Cardiovasc Qual Outcomes. 2019; 12(7):e005580 
10. Graham R, McCoy MA, Schultz AM. Understanding the Public Health Burden of Cardiac Arrest: The Need for National Surveillance. Strategies to Improve Cardiac Arrest Survival: A Time to Act: National Academies Press (US); 2015.

11. Cummins RO. Emergency medical services and sudden cardiac arrest: the" chain of survival" concept. Annu Rev Public Health. 1993;14(1):313-33. https://doi.org/10.1146/annurev.pu.14.050193.001525.

12. Gräsner J-T, Bossaert L. Epidemiology and management of cardiac arrest: what registries are revealing. Best Pract Res Clin Anaesthesiol. 2013;27(3): 293-306. https://doi.org/10.1016/j.bpa.2013.07.008.

13. Lurie KG, Nemergut EC, Yannopoulos D, Sweeney M. The physiology of cardiopulmonary resuscitation. Anesth Analg. 2016;122(3):767-83. https:// doi.org/10.1213/ANE.0000000000000926.

14. Neumar RW, Shuster M, Callaway CW, Gent LM, Atkins DL, Bhanji F, et al. Part 1: executive summary: 2015 American Heart Association guidelines update for cardiopulmonary resuscitation and emergency cardiovascular care. Circulation. 2015;132(18_suppl_2):S315-S67.

15. Edwards-Jackson N, North K, Chiume M, Nakanga W, Schubert C, Hathcock A, et al. Outcomes of in-hospital paediatric cardiac arrest from a tertiary hospital in a low-income African country. Paediatr Int Child Health. 2020; 40(1):11-5. https://doi.org/10.1080/20469047.2019.1570443.

16. Kabbani MS, Alsumih NA, Alsadun SA, Hamadah HK. Five-year survival, performance, and neurodevelopmental outcome following cardiopulmonary resuscitation after pediatric cardiac surgery, preliminary investigation in a single-center experience. J Saudi Heart Assoc. 2019;31(4): 161-9. https://doi.org/10.1016/j.jsha.2019.05.035.

17. Nas J, Te Grotenhuis R, Bonnes JL, Furlaneto JM, van Royen N, Smeets JL, et al. Meta-analysis comparing cardiac arrest outcomes before and after resuscitation guideline updates. Am J Cardiol. 2020;125(4):618-29. https:// doi.org/10.1016/j.amjcard.2019.11.007.

18. Moher D, Liberati A, Tetzlaff J, Altman DG, Group P. Reprint-preferred reporting items for systematic reviews and metaanalyses: the PRISMA statement. Phys Ther. 2009;89(9):873-80. https:// doi.org/10.1093/ptj/89.9.873.

19. Hardin AP, Hackell JM. Committee on practice and ambulatory medicine. Age limit of pediatrics. Pediatrics. 2017;140(3):e20172151.

20. Wells G, Shea B, O'Connell D, Peterson J, Welch V, Losos M, et al. NewcastleOttawa quality assessment scale cohort studies. 2014.

21. Hanlon B, Larget B. Analysis of proportions. Department of statistic university of Wisconsin-Madison 2011

22. Pathak M, Dwivedi SN, Deo SV, Sreenivas $V$, Thakur B. Which is the preferred measure of heterogeneity in meta-analysis and why? A revisit. Biostat Biometrics Open Acc. 2017;1:1-7.

23. Egger M, Smith GD, Schneider M, Minder C. Bias in meta-analysis detected by a simple, graphical test. BMJ. 1997;315(7109):629-34. https://doi.org/1 0.1136/bmj.315.7109.629.

24. Appiah J, Salie S, Argent A, Morrow B. Characteristics, course and outcomes of children admitted to a paediatric intensive care unit after cardiac arrest. S Afr J Crit Care. 2018;34(2):58-64. https://doi.org/10.7196/ SAJCC.2018.v34i2.355.

25. Shikuku DN, Milimo B, Ayebare E, Gisore P, Nalwadda G. Practice and outcomes of neonatal resuscitation for newborns with birth asphyxia at Kakamega County general hospital, Kenya: a direct observation study. BMC Pediatr. 2018;18(1):167. https://doi.org/10.1186/s12887-01 8-1127-6.

26. Alten JA, Klugman D, Raymond TT, Cooper DS, Donohue JE, Zhang W, et al. Epidemiology and outcomes of cardiac arrest in pediatric cardiac intensive care units. Pediatr Crit Care Med. 2017;18(10):935-43. https://doi.org/10.1 097/PCC.0000000000001273.

27. Anton-Martin P, Moreira A, Kang P, Green ML. Outcomes of paediatric cardiac patients after 30 minutes of cardiopulmonary resuscitation prior to extracorporeal support. Cardiol Young. 2020:1-10.

28. Barbaro RP, Paden ML, Guner YS, Raman L, Ryerson LM, Alexander P, et al. Pediatric extracorporeal life support organization registry international report 2016. ASAIO J. 2017;63(4):456.

29. Berg RA, Nadkarni VM, Clark AE, Moler F, Meert $K$, Harrison RE, et al. Incidence and outcomes of cardiopulmonary resuscitation in pediatric intensive care units. Crit Care Med. 2016;44(4):798-808. https://doi.org/10.1 097/CCM.0000000000001484

30. Berg RA, Sutton RM, Reeder RW, Berger JT, Newth CJ, Carcillo JA, et al. Association between diastolic blood pressure during pediatric in-hospital cardiopulmonary resuscitation and survival. Circulation. 2018;137(17):178495. https://doi.org/10.1161/CIRCULATIONAHA.117.032270.

31. Beshish AG, Baginski MR, Johnson TJ, Deatrick BK, Barbaro RP, Owens GE. Functional status change among children with extracorporeal membrane oxygenation to support cardiopulmonary resuscitation in a pediatric cardiac ICU: a single institution report. Pediatr Crit Care Med. 2018;19(7):665-71. https://doi.org/10.1097/PCC.0000000000001555.

32. Brown S, Brogan T, McMullan D, Roberts J. 1545: higher-than-expected rates of survival after pediatric recurrent cardiac arrest. Crit Care Med. 2019;47(1): 748. https://doi.org/10.1097/01.ccm.0000552288.63864.d6.

33. Burke CR, Chan T, Brogan TV, McMullan DM. Pediatric extracorporeal cardiopulmonary resuscitation during nights and weekends. Resuscitation. 2017;114:47-52. https://doi.org/10.1016/j.resuscitation.2017.03.001.

34. Foglia EE, Langeveld R, Heimall L, Deveney A, Ades A, Jensen EA, et al. Incidence, characteristics, and survival following cardiopulmonary resuscitation in the quaternary neonatal intensive care unit. Resuscitation. 2017;110:32-6. https://doi.org/10.1016/j.resuscitation.2016.10.012.

35. Geisser D, Brediger S, Larsen S, Fynn-Thompson F, Thiagarajan R, Alexander P. 1529: survival after ecpr in pediatric patients previously supported with ECMO. Crit Care Med. 2020;48(1):740. https://doi.org/10.1097/01.ccm.000064 8024.37540.91.

36. Holmberg MJ, Wiberg S, Ross CE, Kleinman M, Hoeyer-Nielsen AK, Donnino MW, et al. Trends in survival after pediatric in-hospital cardiac arrest in the United States. Circulation. 2019;140(17):1398-408. https://doi.org/10.1161/ CIRCULATIONAHA.119.041667.

37. Hornik CP, Graham EM, Hill K, Li JS, Ofori-Amanfo G, Clark RH, et al. Cardiopulmonary resuscitation in hospitalized infants. Early Hum Dev. 2016; 101:17-22. https://doi.org/10.1016/j.earlhumdev.2016.03.015.

38. Shakoor A, Pedroso FE, Jacobs SE, Okochi S, Zenilman A, Cheung EW, et al. Extracorporeal cardiopulmonary resuscitation (ECPR) in infants and children: a single-center retrospective study. World J Pediatr Congenit Heart Surg. 2019;10(5):582-9. https://doi.org/10.1177/2150135119862598.

39. Torres-Andres F, Fink EL, Bell MJ, Sharma MS, Yablonsky EJ, Sanchez-deToledo J. Survival and long term functional outcomes for children with cardiac arrest treated with extracorporeal cardiopulmonary resuscitation. Pediatr Crit Care Med. 2018;19(5):451-8. https://doi.org/10.1097/PCC. 0000000000001524.

40. Assar S, Husseinzadeh M, Nikravesh AH, Davoodzadeh $H$. The success rate of pediatric in-hospital cardiopulmonary resuscitation in Ahvaz training hospitals. Scientifica. 2016;2016:1-8. https://doi.org/10.1155/2016/9648140.

41. Chen G-L, Qiao Y-R, Ma J-H, Wang J-X, Hei F-L, Yu J. Extracorporeal cardiopulmonary resuscitation in children of Asia Pacific: a retrospective analysis of extracorporeal life support organization registry. Chin Med J. 2018;131(12):1436-43. https://doi.org/10.4103/03 66-6999.233946.

42. Erek E, Aydın S, Suzan D, Yıldız O, Altın F, Kırat B, et al. Extracorporeal cardiopulmonary resuscitation for refractory cardiac arrest in children after cardiac surgery. Anatolian J Cardiol. 2017;17(4):328-33. https://doi.org/10.14 744/AnatolJCardiol.2016.6658.

43. Mok YH, Loke AP, Loh TF, Lee JH. Characteristics and risk factors for mortality in paediatric in-hospital cardiac events in Singapore: retrospective single Centre experience. Ann Acad Med Singap. 2016; 45:534-41.

44. Rathore V, Bansal A, Singhi SC, Singhi P, Muralidharan J. Survival and neurological outcome following in-hospital paediatric cardiopulmonary resuscitation in North India. Paediatr Int Child Health. 2016;36(2):141-7. https://doi.org/10.1179/2046905515Y.0000000016.

45. Adamski J, Nowakowski P, Gorynski P, Onichimowski D, Weigl W. Incidence of in-hospital cardiac arrest in Poland. Anaesthesiol Intensive Ther. 2016; 48(5):288-93. https://doi.org/10.5603/AlT.a2016.0054.

46. Kramer P, Mommsen A, Miera O, Photiadis J, Berger F, Schmitt KR. Survival and mid-term neurologic outcome after extracorporeal cardiopulmonary resuscitation in children. Pediatr Crit Care Med. 2020;21(6):e316-e24. https:// doi.org/10.1097/PCC.0000000000002291.

47. Skellett S, Orzechowska I, Thomas K, Fortune PM. The landscape of paediatric in-hospital cardiac arrest in the United Kingdom National Cardiac Arrest Audit. Resuscitation. 2020;155:165-71.

48. López-Herce J, del Castillo J, Cañadas S, Rodríguez-Núñez A, Carrillo A, Children SSGoCAi. In-hospital pediatric cardiac arrest in Spain. Rev Esp Cardiol (English Edition). 2014;67(3):189-195. 
49. Girotra S, Spertus JA, Li Y, Berg RA, Nadkarni VM, Chan PS, et al. Survival trends in pediatric in-hospital cardiac arrests: an analysis from get with the guidelines-resuscitation. Circ Cardiovasc Qual Outcomes. 2013;6(1):42-9. https://doi.org/10.1161/CIRCOUTCOMES.112.967968.

50. Wu ET, Li MJ, Huang SC, Wang CC, Liu YP, Lu FL, et al. Survey of outcome of CPR in pediatric in-hospital cardiac arrest in a medical center in Taiwan. Resuscitation. 2009;80(4):443-8. https://doi.org/10.1016/ j.resuscitation.2009.01.006.

51. Zeng J, Qian S, Zheng M, Wang Y, Zhou G, Wang H. The epidemiology and resuscitation effects of cardiopulmonary arrest among hospitalized children and adolescents in Beijing: an observational study. Resuscitation. 2013;84(12):1685-90. https://doi.org/10.1016/j.resuscita tion.2013.08.007.

52. Phillips RS, Scott B, Carter SJ, Taylor M, Peirce E, Davies P, et al. Systematic review and meta-analysis of outcomes after cardiopulmonary arrest in childhood. PLoS One. 2015;10(6):e0130327. https://doi.org/10.1371/journal. pone.0130327.

53. Daya MR, Schmicker RH, Zive DM, Rea TD, Nichol G, Buick JE, et al. Out-ofhospital cardiac arrest survival improving over time: results from the resuscitation outcomes consortium (ROC). Resuscitation. 2015;91:108-15. https://doi.org/10.1016/.j.resuscitation.2015.02.003.

54. Gelberg J, Strömsöe A, Hollenberg J, Radell P, Claesson A, Svensson L, et al. Improving survival and neurologic function for younger age groups after out-of-hospital cardiac arrest in Sweden: a 20-year comparison. Pediatr Crit Care Med. 2015;16(8):750-7. https://doi.org/10.1097/PCC.0000000000000503.

55. Chan PS, McNally B, Tang F, Kellermann A. Recent trends in survival from out-of-hospital cardiac arrest in the United States. Circulation. 2014;130(21): 1876-82. https://doi.org/10.1161/CIRCULATIONAHA.114.009711.

56. Strömsöe A, Svensson L, Axelsson ÅB, Claesson A, Göransson KE, Nordberg P, et al. Improved outcome in Sweden after out-of-hospital cardiac arrest and possible association with improvements in every link in the chain of survival. Eur Heart J. 2015;36(14):863-71. https://doi. org/10.1093/eurheartj/ehu240.

57. Yan S, Gan Y, Jiang N, Wang R, Chen Y, Luo Z, et al. The global survival rate among adult out-of-hospital cardiac arrest patients who received cardiopulmonary resuscitation: a systematic review and meta-analysis. Crit Care. 2020;24(1):1-13.

58. Lee SY, Song KJ, Do Shin S, Ro YS, Hong K, Kim YT, et al. A disparity in outcomes of out-of-hospital cardiac arrest by community socioeconomic status: a ten-year observational study. Resuscitation. 2018;126:130-6. https:// doi.org/10.1016/j.resuscitation.2018.02.025

59. Wang HE, Devlin SM, Sears GK, Vaillancourt C, Morrison LJ, Weisfeldt M, et al. Regional variations in early and late survival after out-of-hospital cardiac arrest. Resuscitation. 2012;83(11):1343-8. https://doi.org/10.1016/j. resuscitation.2012.07.013

\section{Publisher's Note}

Springer Nature remains neutral with regard to jurisdictional claims in published maps and institutional affiliations.

\section{Ready to submit your research? Choose BMC and benefit from}

- fast, convenient online submission

- thorough peer review by experienced researchers in your field

- rapid publication on acceptance

- support for research data, including large and complex data types

- gold Open Access which fosters wider collaboration and increased citations

- maximum visibility for your research: over $100 \mathrm{M}$ website views per year

At $\mathrm{BMC}$, research is always in progress.

Learn more biomedcentral.com/submissions 